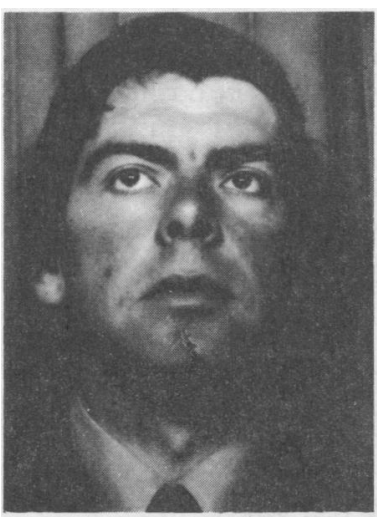

S. Baker

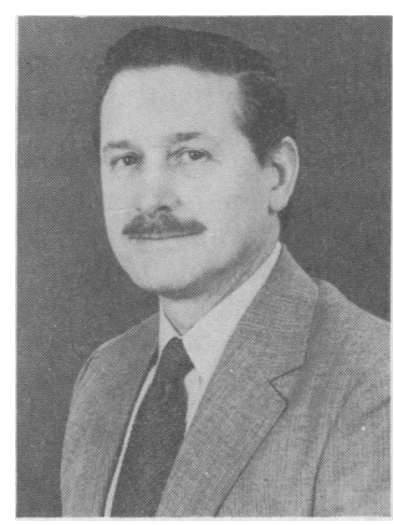

J. Atha

\title{
CANOEISTS' DISORIENTATION FOLLOWING COLD IMMERSION
}

\author{
S. BAKER, MSc, DLC* and J. ATHA, PhD, MAt \\ *Department of Outdoor Education, Bangor Normal College of Education, Bangor, N. Wales \\ tDepartment of Human Sciences, University of Technology, Loughborough, Leics.
}

\begin{abstract}
As an initial step to a broader study of the disorientating effects of cold water immersions on top class competitive canoeists a survey was made of the incidence of hazardous immersions amongst a majority sample of the better canoeists in the country. Virtually the entire entry to one of the most important national competitive meets was canvassed. A total of 288 canoeists in the 1 st and 2 nd divisions were identified and asked to participate. Replies were received from $247(86 \%)$.
\end{abstract}

All those responding had had extensive experience of canoeing in winter spate and were capable of fast and efficient first-time canoe rolls in cases of capsize. Particular interest was focussed on the $85(34 \%)$ who had experienced at least one capsize in cold water during training or competition in mid-winter.

Respondents viewed the winter capsize seriously. Despite their familiarity with the conditions in which they trained all 85 , recalling their capsize experiences, reported being concerned, most (79\%) only modestly so, but a significant proportion $(21 \%)$ confessed to feelings of extreme alarm.

A number of marked physical symptoms that regularly attend on a capsize were widely reported, the most usual of which was severe pain in the forehead $(89 \%)$ and breathing and speaking difficulties when afloat $(64 \%)$. Additionally $62 \%$ reported sensory problems including visual difficulties, dizziness and disorientation. Five canoeists admitted fainting.

Despite these hazards few preventive measures were taken and clothing with negligible thermal insulation properties was commonly worn. It is concluded that transient cold immersions can be disturbing, and can disorientate the canoeist, but that although conscious of this and to his own potentially high cost, he takes little notice of it in his desire to compete successfully.

\section{INTRODUCTION}

Canoeists capsize frequently during training. To the skilled who can execute an immediate recovery roll the incident lasts barely two seconds, and consequently is treated as of little consequence. Slalom canoeists, however, if interested in achieving success in national and international competition must practice in the roughest and fastest water available; in this country 
this means training in winter, in mountainous terrain and when the river is in full spate. Thus both water and ambient air temperatures, to which the canoeist is exposed for long periods, are likely to be low.

The need for good protective clothing in such situations seems clear, but the ambitious canoeist demanding unfettered freedom for his paddling is strongly inclined to cast off his restrictive garments to gain the last ounce of benefit from his efforts. In consequence he, in conjunction with his fellows, adopts the almost classical garments: buoyancy aid, plastic crash hat and nylon cagoule. The question arises, therefore, are the dangers of brief cold immersion overrated or do they exist only to be ignored until disaster strikes? That it may often be the latter was brought home forcibly to one of the authors (SB) by the tragic death of a close friend and fellow competitor (RB), who, during training, drove his canoe into a violent standing wave. The sudden stop caused his foot to be thrust beyond his footrest and become wedged there. He capsized, and could escape neither from canoe nor standing wave. He remained buoyed up, with head above water but rapidly lost interest in rescue attempts and before the equipment required to reach him could be found and put to use he had died from cold exposure.

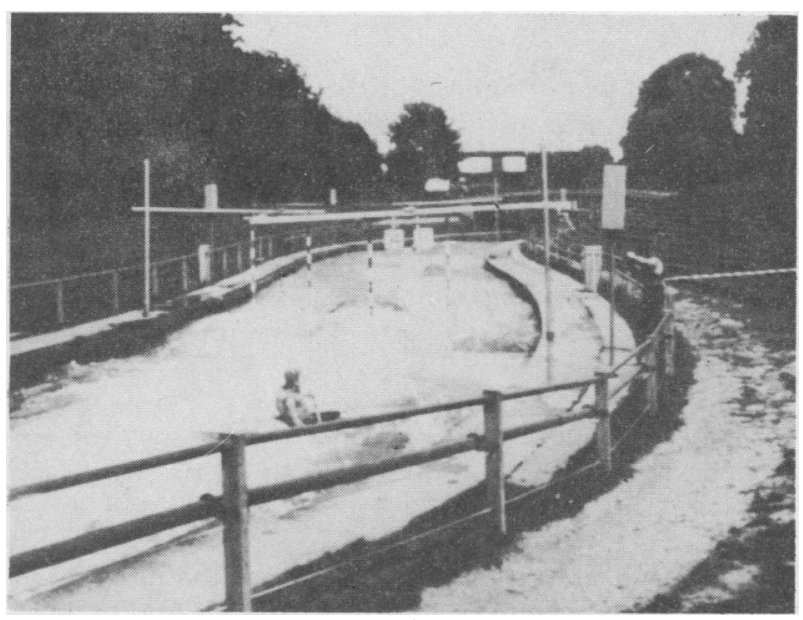

Less sustained immersions may be less hazardous. Yet, even if transient, they may still be disturbing, undermining the function and eating up the reserves of the competitive canoeist. To determine whether disturbing effects do follow from fleeting immersions in cold water, a survey was carried out amongst national class canoeists. This survey, a preliminary to a broader study of immersion disorientation, is reported below.

\section{METHOD}

All entrants, with the exception of five who could not be located in time, participating in one of the most important national competitive meetings in the country, were canvassed personally and asked to participate in the survey. Each individual was given an outline of the nature of the investigation - but not its purposes, to avoid bias in answers - and asked to complete a questionnaire. The questions, some forced choice and some open ended, covered details of personal and competitive history, training experience, competitive success, details of habitual clothing and incidences of accidental hazards, etc. The answers to these questions were then collated, and some are now presented.

\section{RESULTS}

A generous response, i.e. 247 (86\%) of the 288 entrants approached, was obtained (Table 1). Respondents were aged between 15 and 35 years, had at least three years of competitive experience, were highly skilled, being of national or international gradings, and were capable of fast and efficient first-time canoe rolls.

\section{TABLE I}

\section{Questionnaire returns}

$\begin{array}{lrr} & \text { Number } & \% \\ \text { Number approached } & 288 & 100 \% \\ \text { No response } & 41 & 14 \% \\ \text { Total returns } & 247 & 86 \% \\ \begin{array}{l}\text { Frequency among returns } \\ \text { of cold water capsizes in } \\ \text { winter }\end{array} & 85 & 34 \%\end{array}$

Particular interest was focussed on those respondents who had had experience of capsizing in cold water. This group of 85 constituted about a third $(34 \%)$ of the total. They viewed the capsize in mid-winter with respect. Recalling their capsize experiences (Table II) all reported feeling concern, $79 \%$ only moderately so, but $21 \%$ said they had experienced extreme alarm at the incident. The same incidents during training sessions in warm water produced no comparable feelings of disquiet.

The conditions under which skilled canoeists capsize may usually be classed as severe and are often extremely hazardous. Inhospitable gorges accommodate the spate conditions demanded by the canoeist and it is hardly surprising that in such noisy, confined and turbulent environments, apprehension, and often fear, flourish readily.

The most common physical symptom (89\% incidence) resulting from accidental immersion, was a severe pain in the forehead. For many of the respondents this forehead pain was a vice-like grip between the temples 


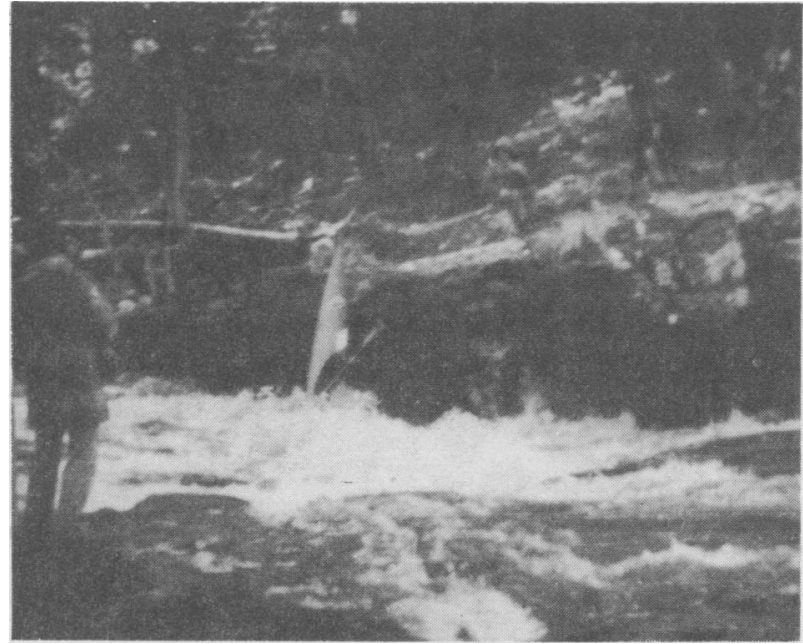

TABLE II

Attitudes and disturbances associated with capsizing in both cold water and pleasantly warm water.

Condition
Attitudes and
Disturbances
Number capsized
Some concern
Extreme alarm
Pain in forehead
Breathing/speaking
difficulties
Numbness in hands
Muscular tension
Disorientation, dizziness
and visual problems
Fainting

\begin{tabular}{|c|c|c|c|}
\hline \multicolumn{2}{|c|}{$\begin{array}{l}\text { Very Cold Water } \\
\text { less than } 8^{\circ} \mathrm{C}\end{array}$} & \multicolumn{2}{|c|}{$\begin{array}{l}\text { Pleasantly Warm } \\
\text { more than } 21 \mathrm{C}\end{array}$} \\
\hline \multicolumn{2}{|c|}{$n=85$} & \multicolumn{2}{|c|}{$n=85$} \\
\hline 85 & $(100 \%)$ & 85 & $(100 \%)$ \\
\hline 67 & ( 79\%) & 0 & ( $0 \%)$ \\
\hline 18 & (21\%) & 0 & $(0 \%)$ \\
\hline 76 & ( 89\%) & 3 & $(4 \%)$ \\
\hline 54 & ( 64\%) & 0 & ( $0 \%)$ \\
\hline 48 & ( 56\%) & 0 & ( $0 \%)$ \\
\hline 3 & ( 4\%) & 3 & $(4 \%)$ \\
\hline 53 & (62\%) & 10 & $(12 \%)$ \\
\hline 5 & ( 6\%) & 0 & ( $0 \%)$ \\
\hline
\end{tabular}

which formed the most vivid experience of the immersion. In no case was the pain attributable to blows to the head, e.g. from objects such as submerged rocks. Pain in the forehead has not been reported in other studies of cold immersion although Jones (1974) observed that it was a common experience among mountaineers exposed to cold and wet conditions.

Breathing problems while afloat following immersion were recorded .by $64 \%$ of the sample. This was not unexpected in view of the findings of Keatinge, Mcllroy and Goldfien (1964) who showed that cold irrigation of the chest produced hyperventilation. The $\mathrm{CO}_{2}$ washout such hyperventilation produces might, arguably, account also for the many reported symptoms of dizziness.
Five canoeists fainted during their capsize. Fainting is the usual outcome of an interruption of the blood flow to the brain. In two out of the five individuals who reported fainting the black-out followed a particularly hazardous section of the river where individuals were forced to roll several times, and to contend with entanglements with underwater obstacles. Their last recollections were of unbearable cold over the whole of their upper, uncovered, body.

Canoeists know well the disadvantages and discomfort of numb hands when canoeing in the cold. Although several insulative gloves have been devised, none provides the positive grip sought by most paddlers. It can be seen from Table II that $56 \%$ of the paddlers suffered from numb hands. Many of the remainder no doubt tolerated them without comment.

It had been assumed that muscle tension pains would also be shown to be a problem for canoeists. These pains, not the unmistakable cramps that can occur, but the more persistent aches frequently seen in the forearms of the novice as a result of unnecessarily forceful or awkward gripping of the paddle loom, were considered likely to develop when skin temperatures fell sufficiently (Clark, 1961) to inhibit normal manual dexterity. Gados (1958) has claimed that this can occur even at hand surface temperatures as high as $17.5^{\circ} \mathrm{C}$ $\left(63.5^{\circ} \mathrm{F}\right)$. This hunch about muscle pains was quickly dispelled by the results of the survey. Despite the high incidence of numb hands mentioned above no pains in muscles were reported.

As the effects of immersion are influenced by the properties of the clothing worn, the normal attire of canoeists was determined (Table III). It is clear from the table that the nylon anorak, worn regularly by $80 \%$ of the sample, is highly popular. It is used almost invariably with a plastic crash helmet. The insulation properties of both, but particularly the anorak, are almost negligible. It thus appears that the majority of canoeists ignore their alarm of capsize, ignore their own beliefs in the likely disturbances resulting from cold by neglecting upper body insulation and decide firmly in favour of garments that offer greatest freedom of movement.

The central purpose of the survey was to decide whether or not sensory disturbances might be such a feature of brief capsizes as to warrant their further investigation. At least eight mechanisms could be seen as possible causes of sensory confusion sufficient to interfere with a competitor's post-capsize progress.

1. Instability of reference cues: a tumultuous environment provides few landmarks to enable the canoeist who capsizes suddenly to recall a firm pre-immersion reference frame. Confusion for this reason is part of the normal competitive scene. 


\section{TABLE III}

\section{Protective clothing worn by top class canceists} $(n=247)$

\begin{tabular}{|c|c|c|c|}
\hline Clothing & Number & $\%$ & Insulation P \\
\hline Nylon Anorak & 198 & $80 \%$ & Negligible \\
\hline 'Dry' Suit & 25 & $10 \%$ & Very good \\
\hline 'Wet' Suit Top & 15 & $6 \%$ & Very good \\
\hline Others & 9 & $4 \%$ & Variable \\
\hline TOTAL & 247 & $100 \%$ & \\
\hline \multicolumn{4}{|l|}{ Head Protection } \\
\hline Crash Hat & 212 & $86 \%$ & Negligible \\
\hline 'Wet' Hood & 20 & $8 \%$ & Very good \\
\hline Woollen Hat & 10 & $4 \%$ & Poor \\
\hline Others & 5 & $2 \%$ & Variable \\
\hline TOTAL & 247 & $100 \%$ & \\
\hline
\end{tabular}

2. Visual interference: mechanical pressure on the eyes, or their flooding, could interfere with visual perception.

3. Fear: a sudden realisation of the dangers of capsizing in a thunderous torrent could switch attention from an exocentric to an egocentric perceptual frame.

4. Cold induced hyperventilation: cold stimulation of the skin of the upper body can induce hyperventilation and carbon dioxide washout, and so lead to dizziness.

5. Mechanical vestibular disturbance: shaking or rocking the head can upset the sense of balance and visual control.

6. Caloric vestibular disturbances: cold water in the ears can cause nystagmus and dizziness.

7. Cold shock: sudden and rapid heat loss can lead to the state of shock.

8. Diving reflex: immersion in cold water, particularly of the face and forehead, can lead to an apnaeic diving reflex, resulting in bradycardia and blood shunting changes.

From Table II it can be seen that almost two thirds (62\%) of respondents experienced disorientating effects, including dizziness and visual difficulties after immersion. Since this group is over five times as large as the group who experienced similar effects following rolling practice in a swimming pool, then it may be assumed that the environmental conditions and particularly the cold exerted significant disturbing influences.

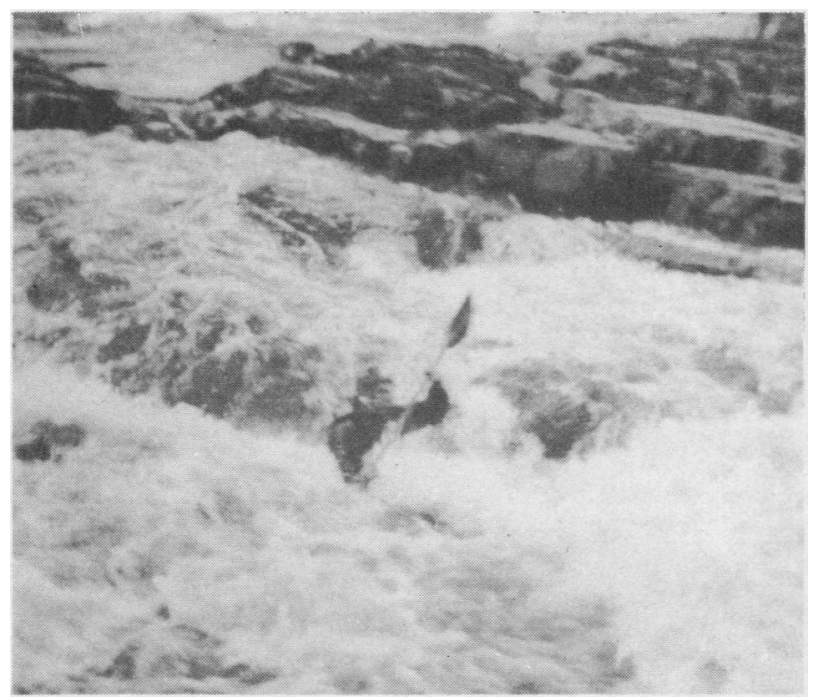

The fact that some disorientation occurred in both warm and cold conditions suggests that not only thermal, but also mechanical factors, perhaps acting through the vestibular apparatus during rolling, were to some degree responsible. If so, then the effects of capsize in a thunderous torrent must be expected to exert even more severe effects. Although man has shown his ability to adapt to angular accelerations (Graybiel and Brown, 1951, (King, 1961) canoeists find themselves subject to such randomly severe disturbances that the chances are probably remote of them becoming conditioned.

Disorientation associated with nystagmus, can be produced artificially by irrigating the ears in cold water (Eviator and Eviator, 1974). This produces convection currents in the endolymph of the labyrinth and deceives the brain as to its cause. However, the volume of the external auditory meatus is only 4-5 $\mathrm{ml}$ and once filled, flow within the orifice is likely to be slight, so it would seem that the effects from this source should not be great. However, the coldness of the water might be sufficient to produce some disorientation.

Whatever the cause of the effects, however, and there was no intention to seek causes in this survey, there does seem to be a widespread belief that disturbing effects follow from a capsize in cold water, that these effects are not trivial, and that significant disorientation and dizziness can follow.

\section{CONCLUSIONS}

It is concluded that transient cold immersions produce important disturbing effects on canoeists. Canoeists, however, appear to take singularly little notice of them, to their potential disadvantage. 


\section{REFERENCES}

Clark, R. E., 1961 "The limiting hand skin temperature for unaffected manual performance in the cold". Journal of Applied Psychology 45 (3): 193-194.

Eviatar, A. and Eviatar, L., 1974 "A critical look at the cold calorics". Arch Otolaryngol. 99 (5): 361-5.

Gados, H. F., 1958 "Effect on complex manual performance of cooling the body while maintaining the hands at normal temperature". Journal of Applied Physiology, 12: 373-376.

Graybiel, A. and Brown, R. H., 1951 "The delay in visual re-orientation following exposure to a change in direction of a resultant force on a human centrifuge". Journal of General Psychol. 45: 143-150.

King, B. G., 1961 "Physiological effects of postural disorientation by tilting during weightlessness". Aerospace Med. 32: $137-140$.

Kobrick, J. L., 1965 "Effect of exposure to low ambient temperatures and wind on visual acuity". Journal Engin. Psych. 4: 92-98.

Wade, N. J., 1968 "Visual orientation during and after lateral head, body and trunk tilt". Perception and Psychophysics, 3: 215-219.

Jones, I., 1974. Mountain Rescue Organisation Handbook (Bangor; Paragon).

Keatinge, W. R., Mcllroy, M. B. and Goldfein, A., 1964 "Cardiovascular responses to ice-cold showers". Journal of Applied Physiology, 19: 1145.

King, B. G., 1961 "Physiological effects of postural disorientation by tilting during weightlessness". Aerospace Medicine, 32: 137-140.

\section{BRITISH ASSOCIATION OF SPORT AND MEDICINE}

Hon. Treasurer:

Dr. H. EVANS ROBSON

39 Linkfield Road,

Mountsorrel,

Loughborough, Leics.

Phone: 0533-303971 Home

SUBSCRIPTIONS - 1981 0533-303436 Surgery

Despite the prominant announcement in the December issue of this journal that ALL SUBSCRIPTIONS WERE DUE ON JANUARY 1st 1981, and PERSONAL REMINDERS having been sent to ALL THOSE IN ARREARS, there are still a large number of unpaid subscriptions. These should be paid IMMEDIATELY, allowing 55 pence for any cheque NOT drawn in STERLING on a UNITED KINGDOM BANK. Rates for 1981 remain at:-

$\begin{array}{llll}\text { Affiliated organisations } & £ 8 & \text { Non-member "Library" subscriptions } & £ 5 \text { U.K. } \\ \text { Ordinary membership } & £ 5 & \text { Overseas, but paid in Sterling } & £ 6 \\ \text { Joint (Husband \& Wife) } & £ 6 & \text { Overseas, Foreign cheques } & \$ 15 \text { U.S. }\end{array}$

Retired from employment $\quad £ 3$

Students

$£ 2$

The high cost of postage and of secretarial assistance makes the sending of reminders expensive, around $15 \%$ of the annual subscription, and wastes much time and effort, preventing more productive work from being done, and being one not unimportant factor that necessitates a rise in subscription rates for 1982. Scottish subscriptions should be sent to the Scottish Area Treasurer, Mrs. E. Snodgrass, 54 lain Road, Bearsden, GLASGOW. All other subscriptions and notifications of changes of title, name and address must BE SENT TO THE TREASURER AS SOON AS POSSIBLE, at the address above. 